\title{
The Acquisition of Prefix and Particle Verbs in German: Evidence from CHILDES
} Evelyn Richter (evelyn.richter@gmail.com)

While the behavior of German particle verbs in contrast to prefix verbs has fascinated morphologists and syntacticians, little research has been done on the acquisition of such verbs. This paper investigates errors children do and do not make, using German child language data from CHILDES (the Child Language Data Exchange System).

Theoretical Background: Prefix and particle verbs in German differ in their morphological composition and behavior as well as in their syntactic behavior (see Zeller 2001). In main clauses, German verbs undergo a transformation that moves them from the sentence-final position to the second position (V2). A prefix verb moves to the second position in its entirety (see (1)), while only the verbal root of a particle verb moves, the particle remaining in its original position (see (2)).

(1) Ich be- 'komme ein Kind $t_{i}$.

I PREF-come a child

'I am having a child.'
(2) Ich male das Bild 'aus $t_{i}$.

I draw the picture PART

'I am coloring the picture'

Furthermore, the prefixal part of the past participle circumfix ge- does not surface in prefix verbs (see (3)), but does with particle verbs, emerging between the particle and the verbal root (see (4)).

\section{(3) Ich habe ein Kind o- be- 'kommen. $\quad$ (4) Ich habe das Bild 'aus- ge- malt. \\ I have a child PERF- PREF-come I have the picture PART-PERF-draw \\ 'I (have) had a child.' 'I (have) colored the picture.'}

Several analyses have been proposed for the behavior of particle verbs (i.a. Dressler 2006, Snyder 2001 and Zeller 2001). The hypotheses in this paper are based on Zeller's analysis of prefix and particle verbs according to which prefix verbs are simplex entities while particle verbs are complex entities. He argues that "the particle and the base verb are independent heads [...] and do not form a word" (2001: 53). This theory accounts for the particle's remaining in sentence-final position and for the insertion of ge- between the particle and the verb.

Hypotheses : Adults clearly distinguish prefix and particle verbs with regard to sentential word order and past participle formation. The errors children make and do not make can provide insight into whether children also distinguish them. A potential null hypothesis assumes that children cannot distinguish prefix and particle verbs. This claim predicts errors such as the prefix splitting from the verbal root and remaining in sentence-final position (see (5)) or the particle being moved to $\mathrm{V} 2$ alongside the verbal root (see (6)).
(5) *Ich komme ein Kind be- $t_{i}$.
I come a child PREF-
(6) *Ich an- komme zu Hause $t_{i}$.
I PART-come at home
'I arrive at home.'
'I am having a child.'

However, our hypothesis claims that children can distinguish simplex and complex entities. If both our hypothesis as well as Zeller's analysis of prefix verbs as simplex and particle verbs as complex entities hold, then we can expect the following: 
1) Prefix verbs are not split in V2 movement.

2) Perfective ge- is not inserted between the prefix and the verbal root.

3) The particle always remains in sentence-final position.

4) Perfective ge- is not aligned before the particle.

5) Perfective ge- is not dropped in the perfect formation of particle verbs.

Methodology: This project uses transcriptions of one child's data recorded from age 1;9.11 to 4;0.06 from the Miller corpus (1979) in the CHILDES database. Initially, one prefix (be-) and one particle (aus) were chosen randomly and all their occurrences extracted. During the result evaluation, however, all possible prefixes were included due to their lower frequency. I wrote my own Perl script to extract relevant data from the corpus, because existing software such as CLAN or AntConc did not return the data in an easily accessible format. The script was limited to results that contained a prefix, the particle aus or ge-. Only a manual analysis of all the data could catch every single occurrence of the dropping of those sequences.

Evaluation of Results: The data contained a range of errors the child made in the production of prefix and particle verbs. However, I decided to differentiate between errors that are relevant to this study and errors that are not. The latter category contains errors such as mispronunciations or missing inflectional suffixes. It is irrelevant for this study whether the child pronounces a prefix correctly as long as the prefix is produced in some form. Hence, I decided to not include these kinds of errors in the following evaluation. Graph 1 shows the different types of relevant errors:

\section{Relevant Errors}

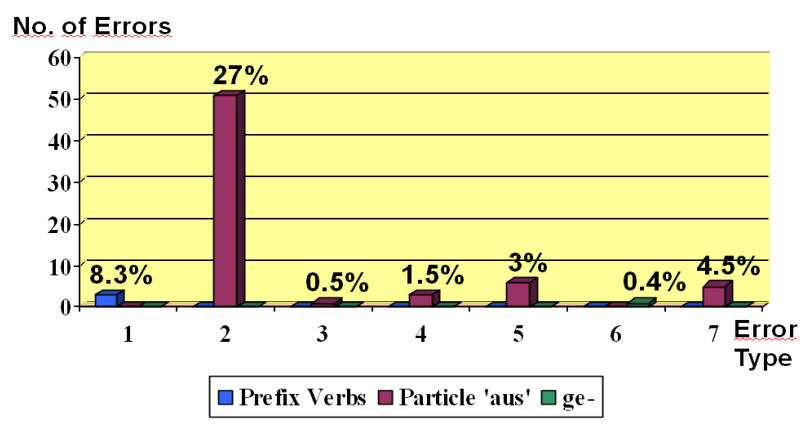

1 Prefix used instead of ge-

2 Verbal part of particle verb dropped

3 Particle of particle verb dropped

4 Prefixal part ge- of past participle dropped

5 Particle moved to sentence-initial position

6 Prefix dropped, ge- used instead

7 Other

Graph 1: Relevant Errors with Prefix and Particle Verbs

These errors are best illustrated in the form of examples from the actual corpus data. As shown in example (7), the child sometimes used a prefix instead of using ge- to form the past participle.

(7) *da sind alle verloren ver-gangen [...] there are all lost PREF-gO.PAST.PCPL 'All were lost there [...]'
(8) $d a$ sind alle verloren ge- gangen there are all lost PERF-go.PAST.PCPL 'All were lost there, Maxe'

A closer look reveals that the child actually only makes a wrong lexical choice by simply picking the wrong verb altogether. However, the child uses the wrong verb in a grammatically correct way, namely she does not use ge- with a prefix verb. The fact that the child selects a prefix verb in place of a simple verb supports the theory of prefix verbs being single lexical entities. 
The most frequent relevant error is the dropping of the verbal part of the particle verb (see (9)). This error occurs most frequently at the 2 word stage and decreases as window of expression increases.

(9) *Schuhe aus shoes PART

'[I want to] take [my] shoes off'
(10) [Ich will meine] Schuhe aus- ziehen. I want my shoes PART- take '[I want to] take [my] shoes off'

The inverse of the above error, namely the dropping of the particle of the particle verb, also occurs (see (11)).
(11) *zieh(e)n, aus- zieh(e)n
take PART-take
'take off, take off'
(12) aus- zieh(e)n, aus- zieh(e)n
PART-take PART-take
'take off, take off'

These two errors support the theory of the particle as a separate lexical head. When the child can express 2 lexical heads, she has to choose between the particle or the verbal root of the particle verb if she also wants to express an object. The particle seems to be chosen more frequently than the verbal root. However, the difference in percentages might come from the limitation of the extraction script to actually occurring sequences and some the occurrences of aus on its own could have been the usage of the preposition aus.

Example (13) shows the dropping of the prefixal part of the past participle of particle verbs contrary to our expectations according to the experimental hypothesis. However, the error occurs very infrequently $(1.5 \%)$ with the particle aus and can therefore be counted towards a certain amount of experimental noise. Furthermore, the child uses the same verb form correctly in her next utterance after this particular example.
(13) *aus-kippt
PART-turn
'turned over/thrown everything out'
(14) aus- ge- kippt
PART-PERF-turn
'turned over/thrown everything out'

Another error occurring in the data contrary to my hypothesis is the movement of the particle to the sentence-initial position along with the verbal part of the particle verb (see (15)). This error in the word order occurs rather infrequently as well (3\%) and can therefore count as noise.
(15) *aus-pust-e mal
(16) Pust-e [die Kerze] mal aus
PART-blow-IMP once
blow-IMP the candle once PART
'Blow [the candle] out'
'Blow [the candle] out'

Lastly, the error of prefix dropping in favor of ge-shall be mentioned here. Example (17) illustrates this error in comparison to the corrected sentence in (18).

$(17) *[. .$.$] unter die \underline{\text { der }}$ Decke [...] runter ge- steckt

below the-ACC the-DAT blanket below PERF-put

'[he] (has) hid below the blanket' 
(18) [...] unter der Decke ver- steckt

below the-DAT blanket PREF-put

'[he] (has) hid below the blanket'

However, the child seems to be uncertain about the lexical choice in this particular example. She does not form an ungrammatical past participle. Instead of using the verb verstecken, she uses the verb stecken. The child's uncertainty about whether to use the accusative or dative article before Decke leads to this analysis. Hence, the child does not drop the prefix. She does not use a prefix verb at all, but uses a simple verb instead. This uncertainty on the child's side again suggests that both prefix and simple verbs are single lexical entities.

Conclusions: My results clearly indicate that children distinguish prefix and particle verbs. There are certain errors which the child does not make which include:

1) The prefix of a prefix verb is not dropped in the past participle formation.

2) Prefix verbs are not split in V2 movement.

3) $g e$ - is not attached to a prefix verb.

4) ge- is not attached before the particle.

A possible explanation might be contrasting stress patterns. All prefixes are unstressed, particles always stressed. However, Atkinson-King suggests that stress is acquired only by the age of 6 (see 1973: 135). Hence, children may not be able to use stress as a distinguishing factor as early as the age of 2 .

Further research would be required to support my hypotheses and the results provided in this paper. A starting point would be a comparison of frequencies of occurrences of prefix verbs in German adult language data to determine whether prefix verbs are less frequent overall or really acquired later. Furthermore, the data search could be expanded to all possible particles and more children in order to account for some of the errors that seem to challenge my hypotheses.

Additionally, a manual analysis could provide more evidence for the dropping of prefix, particle and $g e$ - sequences.

\section{References}

Atkinson-King, Kay (1973). "Children's Acquisition of Phonological Stress Contrasts". Working Papers in Phonetics 25. UCLA.

Dressler, Wolfgang U. (2006). "Compound Types". The Representation and Processing of Compound Verbs. Oxford: Oxford University Press, 23-44.

"Germanic Corpora". CHILDES Database Manuals. Last retrieved: 12/11/2008. http://childes.psy.cmu.edu/manuals/07germanic.pdf.

MacWhinney, B. (2000). The CHILDES project: Tools for analyzing talk. Third Edition. Mahwah, NJ: Lawrence Erlbaum Associates.

Miller, M. (1979). The Logic of Language Development in Early Childhood. Berlin: Springer.

Snyder, William (2001). "On the Nature of Syntactic Variation: Evidence from complex predicates and complex word-formation”. Language. Vol. 77, 324-342.

Zeller, Jochen (2001). Particle Verbs and Local Domains. Amsterdam: John Benjamins. 